\title{
A Gastric Metastatic Lesion That Resembled Early-Stage Gastric Cancer on Endoscopy during Treatment for Recurrent Breast Cancer: A Case Report
}

\author{
Yukino Watanabe ${ }^{a, b}$ Yoshiya Horimoto $^{b}$ Yuka Takahashi $^{\mathrm{a}, \mathrm{b}}$

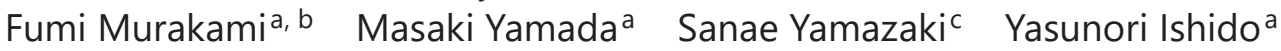 \\ aDepartment of Surgery, Saiseikai Kawaguchi General Hospital, Kawaguchi, Japan; \\ bepartment of Breast Oncology, Juntendo University School of Medicine, Tokyo, Japan; \\ 'Department of Pathology, Saiseikai Kawaguchi General Hospital, Kawaguchi, Japan
}

\section{Keywords}

Breast cancer - Gastrointestinal metastasis - Gastric cancer · Gastrointestinal endoscopy

\begin{abstract}
Breast cancer metastasis to the gastrointestinal tract is relatively rare. Patients with such disease often develop gastrointestinal symptoms, but it is sometimes asymptomatic. Endoscopic findings of gastric metastasis from breast cancer markedly vary from benign to malignant, and even in suspected malignant cases, it is often difficult to differentiate between primary and metastatic disease. We experienced a case in which an endoscopic examination performed during the treatment for metastatic breast cancer resembled an early-stage gastric cancer. A 71-year-old woman underwent curative surgery for right breast cancer 16 years previously. She underwent endoscopic submucosal dissection for early-stage gastric cancer 5 years ago. Two years ago, she developed metastatic disease in the lungs and mediastinal lymph nodes, and endocrine therapy was administered. At the same time, a follow-up endoscopy revealed a new elevated lesion, suspected to be an early-stage gastric cancer. However, histological diagnosis of the biopsy was metastasis of breast cancer. One and a half years later, a follow-up endoscopy revealed a gastric lesion that had reduced in size. She is still alive, having received a variety of systemic treatments. Patients with metastatic breast cancer are experiencing prolonged survival. Thus, follow-up endoscopy should be considered after the diagnosis of gastrointestinal metastasis considering the risk of lethal conditions, such as gastrointestinal bleeding and perforation. Our case serves as a reminder to clinicians how difficult
\end{abstract}




\section{Case Reports in Oncology}

\begin{tabular}{l|l}
\hline Case Rep Oncol 2021;14:1719-1724 \\
\hline DOI: 10.1159/000520828 & $\begin{array}{l}\text { ○ 2021 The Author(s). Published by S. Karger AG, Basel } \\
\text { www.karger.com/cro }\end{array}$ \\
\hline
\end{tabular}

Watanabe et al.: Gastric Metastasis of Breast Cancer Resembling Early-Stage Gastric Cancer

it is to determine whether a gastric lesion is primary or metastatic based on endoscopic findings and the importance of communication with endoscopists and pathologists.

(C) 2021 The Author(s).

Published by S. Karger AG, Basel

\section{Introduction}

Distant metastasis of breast cancer is often found in the lungs, liver, and bone, and gastrointestinal (GI) metastasis is relatively rare. In autopsy cases of recurrent breast cancer, GI metastasis has been reported in $2-18 \%$ of cases and gastric metastasis in approximately $5 \%$. The most common histological type that tends to metastasize to GI is invasive lobular carcinoma [1-5].

Patients with GI metastasis usually complain of some clinical symptoms, such as upper abdominal discomfort and pain. However, metastatic lesions may also be found incidentally by endoscopy for screening without any clinical symptoms [3,5-7]. The most common endoscopic finding of gastric metastases from breast cancer is a submucosal tumor-like appearance, but there are a variety of reports describing benign tumor-like findings, such as raised erosions, type 4 gastric cancer-like appearance, and even hyperplastic polyp-like appearance [6-10].

In this study, we report a case in which a gastric lesion suspected to be an early-stage gastric cancer was detected by upper GI endoscopy while the patient was receiving treatment for metastatic breast cancer (MBC). She was diagnosed with gastric metastasis from breast cancer based on histological findings of the biopsy.

\section{Case Presentation}

A 71-year-old woman underwent partial mastectomy and axillary lymph node dissection for right breast cancer at the age of 55. She was diagnosed with invasive ductal carcinoma (estrogen receptor [ER]-positive, progesterone receptor [PgR]-positive, human epidermal growth factor receptor 2 [HER2] 2+, pT1cN1M0 stage IIA; Fig. 1). She received anastrozole and 5-FU for 5 years after the surgery. At the age of 66, she underwent endoscopic submucosal

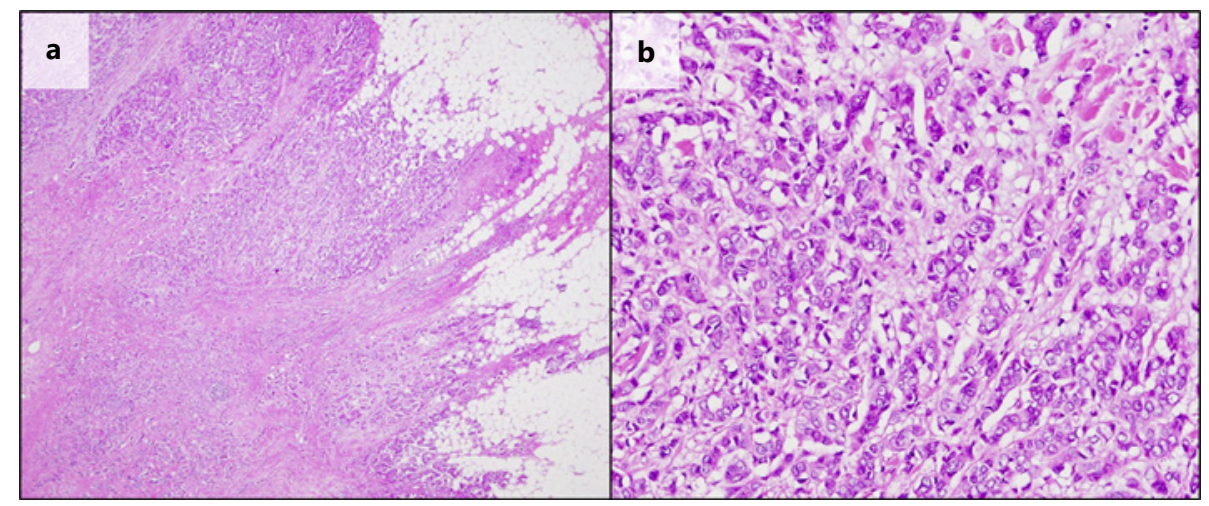

Fig. 1. Histopathological findings of primary breast cancer. Tumor cell infiltration in a small clump or a linear pattern are observed with increase of stromal fiber. $\mathbf{a}, \mathbf{b}$ Hematoxylin and eosin staining. 


\section{Case Reports in Oncology}

\begin{tabular}{l|l}
\hline Case Rep Oncol 2021;14:1719-1724 \\
\hline DOI: 10.1159/000520828 & $\begin{array}{l}\text { @ 2021 The Author(s). Published by S. Karger AG, Basel } \\
\text { www.karger.com/cro }\end{array}$ \\
\hline
\end{tabular}

Watanabe et al.: Gastric Metastasis of Breast Cancer Resembling Early-Stage Gastric Cancer

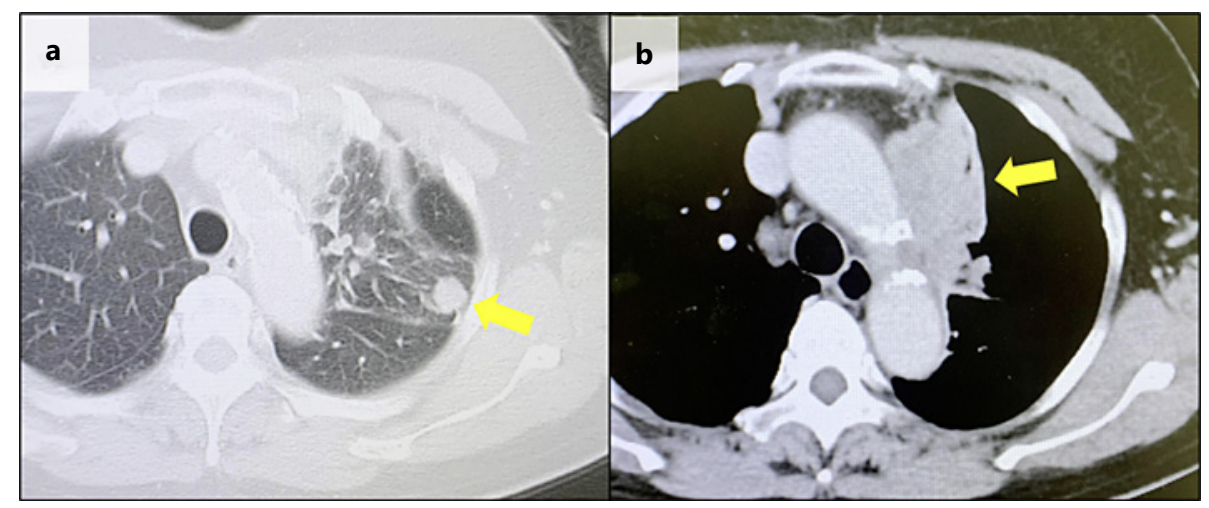

Fig. 2. Contrast-enhanced thoracic CT. a A nodule just below the pleura in the upper lobe of the left lung. b Soft tissue shadow with irregular contrast enhancement in the upper mediastinum was seen.

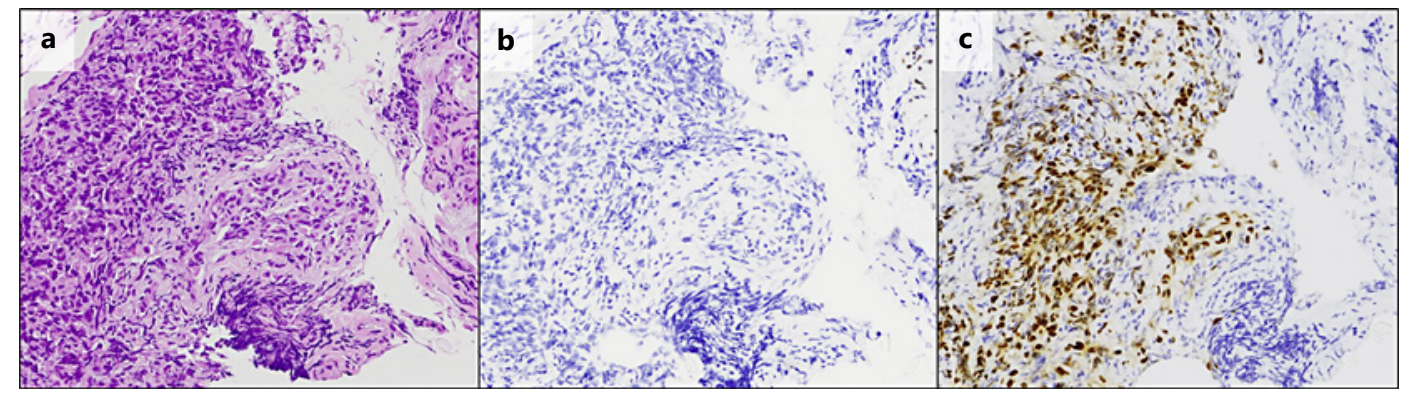

Fig. 3. Pathological findings of lung biopsy. a Outgrowth of atypical cells in part of the bronchial wall tissue. Small glandular spaces and mucus were observed in the cytoplasm of some tumor cells. Immunohistochemical findings of TTF-1 (b) and ER (c).

dissection (ESD) for early-stage gastric cancer in the posterior wall of the lesser curvature of the stomach. Pathological diagnosis was well-differentiated adenocarcinoma (pT1a [M]), and margins were negative. The patient had a history of type 2 diabetes, hypertension, and colorectal polyps. There was no specific family history.

At the age of 69 years ( 14 years after breast cancer surgery), she complained of shortness of breath, and computed tomography (CT) revealed suspected findings of the lung, mediastinal and supraclavicular lymph node metastases (Fig. 2). A transbronchial lung biopsy was performed, and a proliferation of atypical cells with enlarged and irregular nuclei was found in a part of the bronchial wall tissue that was similar to the previous histological findings of breast cancer (Fig. 3). Immunohistochemistry was negative for all markers of lung adenocarcinoma (thyroid transcription factor-1 and napsin A) and endocrine tumor (CD56, synaptophysin, and chromogranin A), while ER-positive, PgR-positive, and HER2-negative. Taken together, her disease was diagnosed lung metastasis of breast cancer. Endocrine therapy (a combination of letrozole and palbociclib, cyclin-dependent kinase 4/6 inhibitor) was started for MBC. At the same time, upper GI endoscopy was performed for follow-up (4 years after ESD), and a new lesion with erythema in the hilar region, away from the ESD, was found (Fig. 4a). The lesion was an elevated erosive lesion with erythema, which was suspected to be IIa-type early-stage gastric cancer. In a biopsy specimen, small lumpy growths of atypical cells in the gastric basal gland mucosa with erosions were observed (Fig. 5). Immunohistochemistry was negative for CDX2, a marker for gastric cancer, and positive for GATA3, that is often positive in breast cancer. Meanwhile, both ER and PgR were positive and 


\section{Case Reports in Oncology}

\begin{tabular}{l|l}
\hline Case Rep Oncol 2021;14:1719-1724 \\
\hline DOI: 10.1159/000520828 & $\begin{array}{l}\text { @ 2021 The Author(s). Published by S. Karger AG, Basel } \\
\text { www.karger.com/cro }\end{array}$ \\
\hline
\end{tabular}

Watanabe et al.: Gastric Metastasis of Breast Cancer Resembling Early-Stage Gastric Cancer

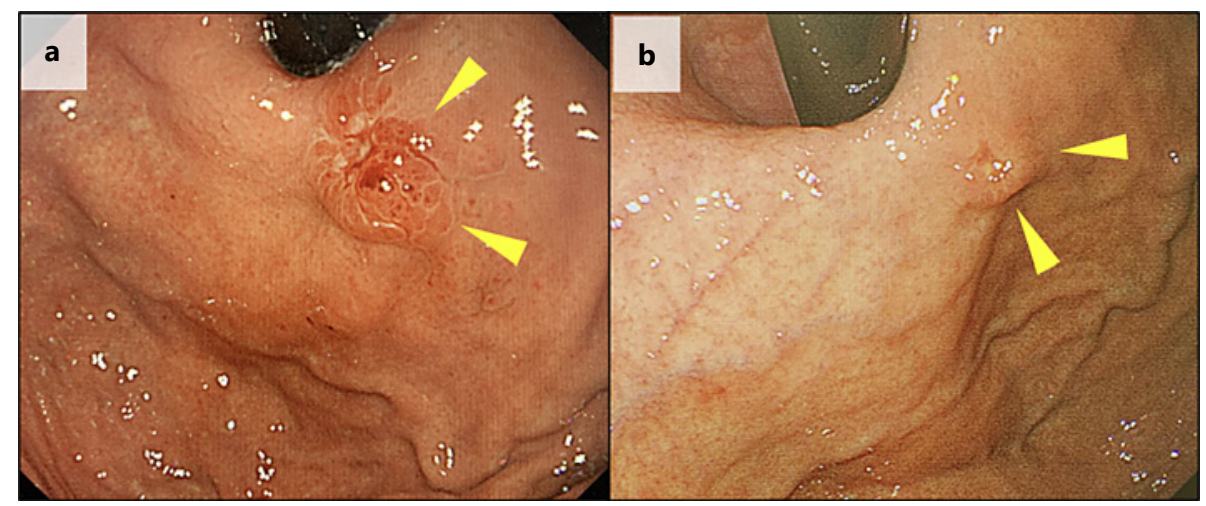

Fig. 4. Gastrointestinal endoscopic findings. a Gastrointestinal endoscopy performed at the time of diagnosis of recurrent breast cancer. Elevated erosive lesion with erythema is seen near the anterior wall of the hilar region. $\mathbf{b}$ Gastrointestinal endoscopy at follow-up showing a reduction in size of the lesion.

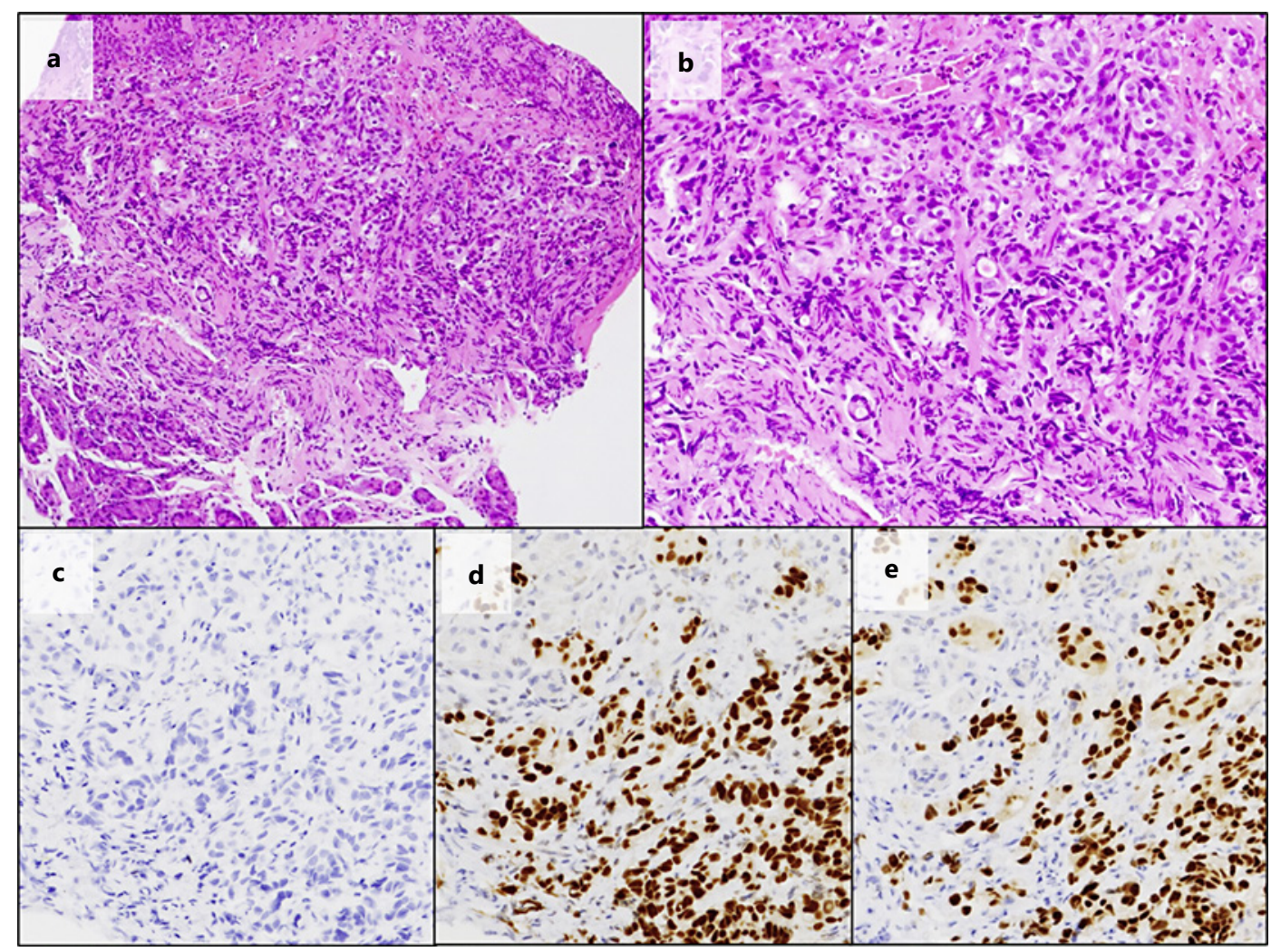

Fig. 5. Histological findings of gastric biopsy. a, b Atypical cells proliferate in the gastric fundic gland mucosal tissue in the form of small clumps, similar to previous right breast cancer. Immunohistochemical findings of CDX2 (c), GATA3 (d), and ER (e).

HER2 was negative. Based on these findings, we made the diagnosis of gastric metastasis of breast cancer.

Eight months after the start of treatment for MBC, she developed liver metastasis, and fulvestrant was administered. Seven months later, lung metastasis became enlarged, and thus a combination of exemestane and everolimus was given. Eleven months later, the liver 
metastasis progressed, and she was started on oral S-1. One month after S-1 administration (1.5 years after the diagnosis of gastric metastasis), upper endoscopy was performed for follow-up. The lesion appeared reduced in size endoscopically (Fig. 4b), although breast cancer cells were confirmed in the repeat biopsy. Seven months after the start of S- 1 therapy, she developed thyroid metastasis, and her systemic treatment was changed to eribulin. She is still continuing the treatment.

\section{Discussion and Conclusion}

Outcomes for patients who have gastric metastasis of breast cancer are poor, averaging 24-month survival after the diagnosis of gastric metastasis $[5,11]$. However, with recent increased treatment options, survival of patients with MBC is expected to be prolonged. Meanwhile, the treatment effects sometimes differ among metastatic organs, and risk of lethal conditions, such as GI bleeding and perforation, should be considered in cases where GI lesions progress [7]. From this perspective, we believe that follow-up GI endoscopy should be considered after the diagnosis of GI metastasis.

Gastric metastasis of breast cancer could appear with various endoscopic findings, from benign to malignant, and even if malignant, the findings are not always consistent. In our case, the findings were suspected to be early-stage gastric cancer, like 0-IIa (surface elevation type). It is important to recognize the difficulty in determining whether a gastric lesion is primary or metastatic disease based on endoscopic findings. For patients with a history of breast cancer, physicians should communicate clinical information to the endoscopists and pathologists.

\section{Acknowledgments}

The authors sincerely appreciate Clear Science Pty Ltd for language editing. We also thank Dr. Atsushi Ikeda at Juntendo University for his advice for interpretation of endoscopic findings.

\section{Statement of Ethics}

This report complies with the guidelines for human studies and includes evidence that the research was conducted ethically in accordance with the World Medical Association Declaration of Helsinki. The authors have no ethical conflicts to disclose. Written informed consent was obtained from the patient for publication of this case report and any accompanying images. The study is exempt from ethics committee approval because the Ethics Committee of Saiseikai Kawaguchi General Hospital admits case reports without ethics committee approval.

\section{Conflict of Interest Statement}

The authors declare that they have no conflicts of interest to disclose.

\section{Funding Sources}

This research did not receive any specific grant from funding agencies in the public, commercial, or not-for-profit sectors.

\section{Karger'}




\section{Case Reports in Oncology}

Case Rep Oncol 2021;14:1719-1724

\begin{tabular}{l|l}
\hline DOI: 10.1159/000520828 & @ 2021 The Author(s). Published by S. Karger AG, Basel \\
\hline
\end{tabular} www.karger.com/cro

Watanabe et al.: Gastric Metastasis of Breast Cancer Resembling Early-Stage Gastric Cancer

\section{Author Contributions}

Y.W., Y.T., F.M., and M.Y. treated this patient. S.Y. conducted pathological diagnosis and provided histological information. Y.W. and Y.H. wrote the manuscript. Y.I. reviewed and edited the manuscript. All authors contributed to discussions and agreed on the final version of the submitted manuscript.

\section{Data Availability Statement}

All data generated or analyzed during this study are included in this article. Further enquiries can be directed to the corresponding author.

\section{References}

1 Mukaiyama T, Ogawa M, Horikoshi N, Inoue K, Inagaki J, Egaki K, et al. Anaysis of metastatic behaviors and causes of death in 100 autopsied patients with breast cancer. Jpn J Breast Cancer. 1989;4:121-6.

2 Arpino G, Bardou VJ, Clark GM, Elledge RM. Infiltrating lobular carcinoma of the breast: tumor characteristics and clinical outcome. Breast Cancer Res. 2004;6:R149-56.

3 Horimoto Y, Hirashima T, Arakawa A, Miura H, Saito M. Metastatic colonic and gastric polyps from breast cancer resembling hyperplastic polyps. Surg Case Rep. 2018;4:23.

4 Koike K, Kitahara K, Higaki M, Urata M, Yamazaki F, Noshiro H. Clinicopathological features of gastric metastasis from breast cancer in three cases. Breast Cancer. 2014;21:629-34.

5 McLemore EC, Pockaj BA, Reynolds C, Gray RJ, Hernandez JL, Grant CS, et al. Breast cancer: presentation and intervention in women with gastrointestinal metastasis and carcinomatosis. Ann Surg Oncol. 2005;12:886-94.

6 Takeuchi H, Hiroshige S, Yoshikawa Y, Kusumoto T, Muto Y. A case of synchronous metastasis of breast cancer to stomach and colon. Anticancer Res. 2012;32(9):4051-5.

7 Güler SA, Şimşek T, Pösteki G, Güreșin A, Çınar S, Onbaşılar U, et al. A very rare reason for gastric perforation, caused by gastric metastasis of breast cancer: case presentation. Eur J Breast Health. 2019;15:59-62.

8 Arrangoiz R, Papavasiliou P, Dushkin H, Farma JM. Case report and literature review: metastatic lobular carcinoma of the breast an unusual presentation. Int J Surg Case Rep. 2011;2:301-5.

9 Kita M, Furukawa M, Iwamuro M, Hori K, Kawahara Y, Taira N, et al. Breast cancer metastasis to the stomach that was diagnosed after endoscopic submucosal dissection. Case Rep Gastrointest Med. 2016;2016:2085452.

10 Eo WK. Breast cancer metastasis to the stomach resembling early gastric cancer. Cancer Res Treat. 2008;40: 207-10.

11 Dos Santos Fernandes G, Batista Bugiato Faria LD, de Assis Pereira I, Neves NC, Vieira YO, Leal AI. Gastric metastasis of breast cancer: a case series. Rare Tumors. 2016;8:6305. 